\title{
Oral and Topical Treatment of Painful Diabetic Polyneuropathy: Practice Guideline Update Summary
}

\author{
Report of the AAN Guideline Subcommittee
}

Raymond Price, MD, Don Smith, MD, Gary Franklin, MD, MPH, Gary Gronseth, MD, Michael Pignone, MD, MPH, William S. David, MD, PhD, Carmel Armon, MD, MSc, MHS, Bruce A. Perkins, MD, MPH, Vera Bril, MD, Alexander Rae-Grant, MD, John Halperin, MD, Nicole Licking, DO, Mary Dolan O'Brien, MLIS, Scott R. Wessels, MPS, ELS, Leslie C. MacGregor, PhD, VMD, JD, Kenneth Fink, MD, MPH, Lawrence B. Harkless, DPM, Lindsay Colbert, MA, and Brian C. Callaghan, MD, MS

Neurology ${ }^{\circledR}$ 2022;98:31-43. doi:10.1212/WNL.0000000000013038

\section{Abstract}

\section{Objective}

To update the 2011 American Academy of Neurology (AAN) guideline on the treatment of painful diabetic neuropathy (PDN) with a focus on topical and oral medications and medical class effects.

\section{Methods}

The authors systematically searched the literature from January 2008 to April 2020 using a structured review process to classify the evidence and develop practice recommendations using the AAN 2017 Clinical Practice Guideline Process Manual.

\section{Results}

Gabapentinoids (standardized mean difference [SMD] 0.44; 95\% confidence interval [CI], 0.21-0.67), serotonin-norepinephrine reuptake inhibitors (SNRIs) (SMD 0.47; 95\% CI, 0.34-0.60), sodium channel blockers (SMD 0.56; 95\% CI, 0.25-0.87), and SNRI/opioid dual mechanism agents (SMD 0.62; 95\% CI, 0.38-0.86) all have comparable effect sizes just above or just below our cutoff for a medium effect size (SMD 0.5). Tricyclic antidepressants (TCAs) (SMD 0.95; 95\% CI, 0.15-1.8) have a large effect size, but this result is tempered by a low confidence in the estimate.

\section{Recommendations Summary}

Clinicians should assess patients with diabetes for PDN (Level B) and those with PDN for concurrent mood and sleep disorders (Level B). In patients with PDN, clinicians should offer TCAs, SNRIs, gabapentinoids, and/or sodium channel blockers to reduce pain (Level B) and consider factors other than efficacy (Level B). Clinicians should offer patients a trial of medication from a different effective class when they do not achieve meaningful improvement or experience significant adverse effects with the initial therapeutic class (Level B) and not use opioids for the treatment of PDN (Level B).

\author{
Correspondence \\ American Academy \\ of Neurology \\ guidelines@aan.com
}

\section{RELATED ARTICLE}

\section{Special Article}

Polyneuropathy Quality Measurement Set: Quality Improvement in Neurology

Page 22 


\section{Glossary}

AAN = American Academy of Neurology; CBT = cognitive behavioral therapy; CDC $=$ Centers for Disease Control and Prevention; CI = confidence interval; COI = conflict of interest; DEA = Drug Enforcement Administration; FDA = Food and Drug Administration; GS = Guidelines Subcommittee; PDN = painful diabetic neuropathy; SMD = standardized mean difference; SNRI = serotonin-norepinephrine reuptake inhibitor; TCA = tricyclic antidepressant.

Diabetes is the most common cause of peripheral neuropathy, accounting for $32 \%-53 \%$ of cases. ${ }^{1-4}$ Painful diabetic neuropathy $(\mathrm{PDN})$ occurs in more than $16 \%$ of patients with diabetes, but physicians do not always discuss this important symptom with patients; therefore, pain often goes untreated. ${ }^{5}$ PDN, even compared with painless neuropathy, negatively affects physical and mental quality of life. ${ }^{6}$

A large, nationally representative health care claims study found that the most common prescriptions for pain associated with peripheral neuropathy were opioids, followed by gabapentin, pregabalin, duloxetine, amitriptyline, and venlafaxine. ${ }^{7}$ The high use of opioids in people with painful neuropathy occurs despite a position statement from the American Academy of Neurology (AAN) and a guideline from the Centers for Disease Control and Prevention (CDC) recommending caution with opioid use in people with chronic noncancer pain. ${ }^{8,9}$ According to the CDC, opioid overdose deaths have accelerated during the pandemic, highlighting the importance of appropriate prescribing. ${ }^{10}$ We aimed to update a 2011 AAN guideline on the treatment of $\mathrm{PDN}^{11}$ and perform metaanalyses of individual medications as well as commonly used medication classes. An update was needed to review a large number of new randomized controlled trials of the treatment of pain in people with PDN and to highlight the alternatives to opioid use in this population. Furthermore, we aimed to evaluate the effects of different medication classes on PDN, whereas most previous guidelines and systematic reviews have focused solely on individual medications. ${ }^{1-14}$ Understanding whether medications of the same class have similar or different effects on pain reduction has implications for optimal treatment of this common condition, such as considering other factors such as cost when choosing between pain medications of the same class and which medications to switch to after a treatment failure. We chose to focus this guideline on oral and topical medications for PDN, but it is important to note that other interventions are also available. Specifically, this guideline seeks to answer the following question: In people with painful diabetic polyneuropathy, what is the efficacy of using oral or topical pharmacologic interventions to reduce pain compared with placebo or an active comparator?

\section{Description of the Analytic Process}

In November 2017, the Guidelines Subcommittee (GS) of the AAN convened a panel of clinicians with expertise in painful diabetic polyneuropathy. The panel included content experts, methodology experts, AAN GS members, and patient advocates/ representatives. Individuals with a clear financial conflict and those whose professional and intellectual bias would diminish the credibility of the review were excluded. A majority $(82 \%)$ of the members of the development panel and the lead author are free of conflicts of interest (COIs) relevant to the subject matter of this practice guideline. Three of the guideline developers (V.B., L.B.H., B.A.P.) were determined to have COIs, but the COIs were judged to be not significant enough to preclude them from authorship. These 3 developers were not permitted to review or rate the evidence, but they did serve in an advisory capacity to help with the validation of the key questions, the scope of the literature search, and the identification of seminal articles, and they participated in the recommendation development process.

The panel searched the MEDLINE, Cochrane, EMBASE, and ClinicalTrials.gov databases from January 2008 to September 2018 for relevant peer-reviewed articles that met inclusion criteria and were in English. The 2011 AAN PDN guideline included articles published prior to August 2008, and we included Class I and II studies from the 2011 guideline in the meta-analyses. The initial search yielded 1,044 articles. The panelists reviewed the article titles and abstracts for potential relevance. Of the reviewed abstracts, 155 were identified as potentially relevant and corresponding articles were obtained for full-text review. Each of the 155 articles was reviewed by 2 panel members working independently of each other. The panelists selected 95 articles for inclusion in the analysis, all of which were selected for evidence rating. The selected articles were required to be randomized controlled trials with more than 20 participants. An updated literature search completed in April 2020 identified an additional 20 potentially relevant articles published since September 2018. From the 2011 guideline, 34 articles were germane to the treatments discussed in this guideline and had been previously rated as Class I or Class II studies.

Risk of bias for each of the $149(95+20+34)$ articles was assessed independently by 2 authors who used the 2017 AAN Clinical Practice Guideline Process Manual criteria. ${ }^{15}$ Any disagreements were reconciled to achieve a final classification. Sixteen of the 149 articles were rejected during the risk of bias classification or because they were deemed not pertinent to our clinical questions or our inclusion/exclusion criteria.

We included only Class I and Class II studies. Where possible, we used outcomes and outcome measures that were prespecified in the articles as the primary outcomes of interest. Otherwise, we used outcomes and outcome measures in the 
same domain as the prespecified primary outcome. When articles reported outcomes at multiple time points, we used the final time point. When articles reported outcomes for different doses of a medication, we pooled the outcomes for all doses into a single measure because no significant differences were observed for lower compared with higher doses of a medication within the same trial. All effect sizes were converted to a standardized mean difference (SMD). We considered an absolute value of $0.2,0.5$, and 0.8 as thresholds for small, medium, and large effect sizes, respectively.

These effect size values were entered into AAN's synthesis tool to calculate a random-effects meta-analysis. The tool also automates implementation of a modified version of the Grading of Recommendations Assessment, Development, and Evaluation (GRADE) process. Because the presence of a robust placebo response is expected in randomized placebocontrolled trials with pain outcomes, we systematically reviewed the placebo response for all included trials. We manually downgraded the directness rating by 1 level for articles in which the group that received placebo showed pain improvement of $<10 \%$ but $>5 \%$ and by 2 levels for pain improvement of $\leq 5 \%$.

For each analysis performed, the synthesis tool generates a clinically relevant conclusion, along with a level of confidence about the conclusion. These conclusions were used to inform our final conclusions and recommendations, which were harmonized via a modified Delphi process to achieve at least an $80 \%$ consensus.

We prespecified 5 oral medication classes to evaluate: gabapentinoids (such as gabapentin and pregabalin), serotoninnorepinephrine reuptake inhibitors (SNRIs) (such as duloxetine, venlafaxine, and desvenlafaxine), tricyclic antidepressants (TCAs) (such as amitriptyline, nortriptyline, imipramine), sodium channel blockers (such as carbamazepine, oxcarbazepine, lamotrigine, valproic acid, lacosamide), and SNRI/opioid dual mechanism agents (such as tramadol and tapentadol). Of note, defining sodium channel blockers as a class is more difficult than other medication classes. The medications above were chosen a priori by the author panel. Topiramate was not included as a sodium channel blocker because it has several mechanisms of action. Of note, no new studies of topiramate were identified since the 2011 guideline.

The panel formulated a rationale for recommendations based on the evidence systematically reviewed and stipulated axiomatic principles of care. This rationale is an explanatory section that precedes each recommendation statement or set of recommendation statements. From this rationale, corresponding actionable recommendation statements were developed. The level of obligation of the recommendations was assigned using a modified Delphi process. "Must" corresponds to Level A, very strong recommendations; "should" to Level $\mathrm{B}$, strong recommendations; and "may" to Level C, weak recommendations.

\section{Analysis of Evidence}

A summary of the analysis is provided in the following. The full-length update, including a more detailed description of the analytic process, can be viewed at aan.com/Guidelines/ home/GuidelineDetail/1038.

\section{Oral Medications}

In people with painful diabetic polyneuropathy, what is the efficacy of using oral pharmacologic interventions to reduce pain compared with placebo or an active comparator?

Tables 1-3 include study dosage and duration data, individual medication efficacy data, and efficacy data by drug class (Figure).

\section{Gabapentinoids}

Gabapentin is probably more likely than placebo to improve pain (SMD 0.53; 95\% confidence interval [CI], 0.22-0.84; medium effect, moderate confidence; 1 Class I study).

Pregabalin is possibly more likely than placebo to improve pain (SMD 0.29; 95\% CI, 0.13-0.45; small effect, low confidence; 8 Class I and 7 Class II studies).

Mirogabalin is possibly more likely than placebo to improve pain (SMD 0.21; 95\% CI, 0.02-0.40; small effect, low confidence; 2 Class II studies).

\section{Gabapentinoid Class Effect}

Gabapentinoids are probably more likely than placebo to improve pain (SMD 0.44; 95\% CI, 0.25-0.63; small effect, moderate confidence; 8 Class I studies and 8 Class II studies). The $\mathrm{I}^{2}$ value for heterogeneity across studies was $86 \%$.

\section{Serotonin-Norepinephrine Reuptake Inhibitors}

Duloxetine is probably more likely than placebo to improve pain (SMD 0.50; 95\% CI, 0.26-0.74; moderate effect, moderate confidence; 2 Class I and 5 Class II studies).

Desvenlafaxine is possibly more likely than placebo to improve pain (SMD 0.25; 95\% CI, 0.07-0.43; small effect, low confidence; 1 Class II study).

\section{SNRI Class Effect}

Three Class $\mathrm{I}^{16-18}$ and 6 Class $\mathrm{II}^{19-24}$ studies were included for medications of this class, including 1 for venlafaxine, 1 for desvenlafaxine, and 7 for duloxetine. SNRIs are probably more likely than placebo to improve pain (SMD 0.47; 95\% CI, 0.34-0.60; small effect, moderate confidence; 3 Class I and 6 Class II studies). I $\mathrm{I}^{2}$ value for heterogeneity was $43 \%$.

\section{Tricyclic Antidepressants}

In addition to 1 new study, 2 Class I or Class II studies were identified for amitriptyline from the systematic review of the 2011 guideline. ${ }^{11}$ Amitriptyline is possibly more likely than placebo to improve pain (SMD 0.95; 95\% CI, 0.15-1.8; large effect, low confidence; 1 Class I study and 2 Class II studies). 
Table 1 Medication Dosage and Duration Information

\begin{tabular}{|c|c|c|c|}
\hline Medication class & Medication & Dosage, mg/d & Duration, wk \\
\hline SNRI & Duloxetine & $40-60$ & 12 \\
\hline SNRI & Venlafaxine & $150-225$ & 6 \\
\hline SNRI & Desvenlafaxine & 200 & 13 \\
\hline Gabapentinoid & Gabapentin & $900-3,600$ & $4-8$ \\
\hline Gabapentinoid & Pregabalin & $300-600$ & $5-12$ \\
\hline Gabapentinoid & Mirogabalin & $15-30$ & 5 \\
\hline $\begin{array}{l}\text { Sodium channel } \\
\text { antagonist }\end{array}$ & Oxcarbazepine & $1,400-1,800$ & 16 \\
\hline $\begin{array}{l}\text { Sodium channel } \\
\text { antagonist }\end{array}$ & Lamotrigine & $200-400$ & 6 \\
\hline $\begin{array}{l}\text { Sodium channel } \\
\text { Antagonist }\end{array}$ & Lacosamide & 400 & 12 \\
\hline $\begin{array}{l}\text { Sodium channel } \\
\text { blocker }\end{array}$ & Valproic acid & $\begin{array}{l}1,000-1,200 \text { or } 20 \\
\mathrm{mg} / \mathrm{kg} / \mathrm{d}\end{array}$ & $4-12$ \\
\hline TCA & Amitriptyline & $75-150$ & 6 \\
\hline Capsaicin & Capsaicin & $\begin{array}{l}8 \% \text { for } 30 \mathrm{~min} / \\
\text { application or } 0.075 \% \\
4 \text { times per day }\end{array}$ & 12 \\
\hline
\end{tabular}

Abbreviations: SNRI = serotonin-norepinephrine reuptake inhibitor; TCA = tricyclic antidepressant.

\section{TCA Class Effect}

No Class I or Class II studies were found for other TCAs; therefore, the best estimate for the class effect is based solely on amitriptyline studies. TCAs are possibly more likely than placebo to improve pain (SMD 0.95; 95\% CI, 0.15-1.8; large effect, low confidence; 1 Class I study and 2 Class II studies). The $\mathrm{I}^{2}$ value for heterogeneity was $80 \%$.

\section{Sodium Channel Blockers}

Valproic acid is possibly more likely than placebo to improve pain (SMD 0.86; 95\% CI, 0.38-1.33; large effect, low confidence; 3 Class II studies).

\section{Sodium Channel Blocker Class Effect}

Five Class II studies were included for medications of this class: 1 lamotrigine, ${ }^{25} 2$ lacosamide, $^{26,27} 1$ oxcarbazepine, ${ }^{28}$ and 1 valproic acid. ${ }^{29}$ Sodium channel blockers are probably more likely than placebo to improve pain (SMD 0.56; 95\% CI, 0.25-0.87; medium effect, moderate confidence; 5 Class II studies). The $\mathrm{I}^{2}$ value for heterogeneity was $80 \%$.

\section{SNRI/Opioid Dual Mechanism Agents}

Tapentadol is possibly more likely than placebo to improve pain (SMD 0.78; 95\% CI, 0.54-1.03; medium effect, low confidence; 1 Class II study).

\section{SNRI/Opioid Class Effect}

Four Class II studies ${ }^{30-33}$ were identified for medications of this class, including 3 tramadol studies from the systematic review of the 2011 guideline. ${ }^{11}$ SNRI/opioid dual mechanism agents are probably more likely than placebo to improve pain (SMD 0.62; 95\% CI, 0.38-0.86; medium effect, moderate confidence; 4 Class II studies). The $\mathrm{I}^{2}$ value for heterogeneity was $59 \%$.

\section{Class Effect Sizes}

Gabapentinoids (SMD 0.44; 95\% CI, 0.21-0.67), SNRIs (SMD 0.47; 95\% CI, 0.34-0.60), sodium channel blockers (SMD 0.56; 95\% CI, 0.25-0.87), and SNRI/opioid dual mechanism agents (SMD 0.62; 95\% CI, 0.38-0.86) all have comparable effect sizes just above or just below our cutoff for a medium effect size (SMD 0.5) (Figure). Although TCAs (SMD 0.95; 95\% CI, 0.15-1.5) may have a large effect size, this result is tempered by a low confidence in the estimate.

\section{Other Oral Medications}

Nabilone, a synthetic cannabinoid, is probably more likely than placebo to improve pain (SMD 1.32; 95\% CI, 0.52-2.13; large effect, moderate confidence; 1 Class I study).

Ginkgo biloba is possibly more likely than placebo to improve pain (SMD 0.83; 95\% CI, 0.48-1.18; large effect, low confidence; 1 Class II study).

ABT 639, a selective voltage-dependent T-type calcium channel blocker that is not available, is probably no more likely than placebo to improve pain (SMD -0.04; 95\% CI, -0.41 to 0.32 ; moderate confidence; 1 Class I study).

ABT 894, a nicotinic acetylcholine receptor agonist that is not available, is probably no more likely than placebo to improve pain (SMD -0.06 ; $95 \% \mathrm{CI},-0.24$ to 0.13 ; moderate confidence; 1 Class I study).

Filorexant, an orexin antagonist that is not available, is possibly no more likely than placebo to improve pain (SMD 0.21; $95 \%$ CI, -0.36 to 0.79 ; low confidence; 1 Class II study).

Tocotrienols, which belong to the vitamin E family, are possibly no more likely than placebo to improve pain (SMD 0.09; $95 \%$ CI, -0.14 to 0.32 ; low confidence; 1 Class II study).

Nutmeg extract is possibly no more likely than placebo to improve pain (SMD -0.01 ; $95 \% \mathrm{CI},-0.46$ to 0.44 ; low confidence; 1 Class II study).

Metanx, consisting of L-methylfolate calcium, algae-S powder pyridoxal-5' -phosphate, and methylcobalamin, is possibly no more likely than placebo to improve pain (SMD -0.43; 95\% CI, -0.86 to 0.001 ; low confidence; 1 Class II study).

PF-05089771, a $\mathrm{Na}_{\mathrm{v}} 1.7$ and $\mathrm{Na}_{\mathrm{v}} 1.8$ voltage-gated sodium channel blocker that is not available, is possibly no more likely than placebo to improve pain (SMD 0.34; $95 \% \mathrm{CI},-0.10$ to 0.78; low confidence; 1 Class I study).

There are insufficient data as to whether ASP8477, a fatty acid amide hydrolase inhibitor that is not available, is more or less 
Table 2 Efficacy of Oral and Topical Medications

\begin{tabular}{|c|c|c|c|c|c|}
\hline Comparison & SMD $^{a}$ & LCL & UCL & $\begin{array}{l}\text { Number } \\
\text { of articles }\end{array}$ & Class \\
\hline ABT 639/placebo & -0.04 & -0.41 & 0.32 & 1 & I \\
\hline ABT 894/placebo & -0.06 & -0.24 & 0.13 & 1 & 1 \\
\hline $\begin{array}{l}\text { Amitriptyline/ } \\
\text { gabapentin }\end{array}$ & 0.33 & -0.32 & 0.98 & 1 & II \\
\hline $\begin{array}{l}\text { Amitriptyline/ } \\
\text { placebo }^{\mathbf{b}}\end{array}$ & 0.95 & 0.15 & 1.76 & 4 & I and || \\
\hline ASP8477/placebo & 0.01 & -0.47 & 0.48 & 1 & ॥ \\
\hline AZD2423/placebo ${ }^{\text {b,c }}$ & -0.45 & -0.87 & -0.04 & 1 & II \\
\hline $\begin{array}{l}\text { Buprenorphine/ } \\
\text { placebo }\end{array}$ & 0.23 & -0.09 & 0.55 & 1 & II \\
\hline Capsaicin/placebob & 0.30 & 0.14 & 0.47 & 2 & I and |I \\
\hline $\begin{array}{l}\text { Citrullus colocynthis/ } \\
\text { placebob }^{\text {b }}\end{array}$ & 0.91 & 0.36 & 1.45 & 1 & II \\
\hline $\begin{array}{l}\text { Desvenlafaxine/ } \\
\text { placebo }^{\text {b }}\end{array}$ & 0.25 & 0.07 & 0.43 & 1 & II \\
\hline $\begin{array}{l}\text { Dextromethorphan + } \\
\text { quinidine/placebo }\end{array}$ & 0.69 & -0.03 & 1.41 & 1 & ॥ \\
\hline $\begin{array}{l}\text { Duloxetine/ } \\
\text { nortriptyline }^{\text {b }}\end{array}$ & 1.64 & 0.63 & 2.65 & 1 & II \\
\hline Duloxetine/placebo ${ }^{b}$ & 0.50 & 0.26 & 0.74 & 7 & I and II \\
\hline $\begin{array}{l}\text { Epalrestat sustained } \\
\text { release/epalrestat } \\
\text { immediate release }\end{array}$ & 0.25 & -0.14 & 0.64 & 1 & II \\
\hline Filorexant/placebo & 0.21 & -0.36 & 0.79 & 1 & II \\
\hline Gabapentin/placebo ${ }^{b}$ & 0.53 & 0.22 & 0.84 & 1 & I \\
\hline $\begin{array}{l}\text { y-Linolenic acid/ } \\
\text { a-lipoic acid }\end{array}$ & 0.34 & -0.12 & 0.80 & 1 & II \\
\hline Gingko biloba/placebob & 0.83 & 0.48 & 1.18 & 1 & II \\
\hline $\begin{array}{l}\text { Glyceryl trinitrate + } \\
\text { valproate/placebo }\end{array}$ & 1.14 & 0.52 & 1.77 & 1 & II \\
\hline $\begin{array}{l}\text { Glyceryl trinitrate/ } \\
\text { placebob }^{\text {ala }}\end{array}$ & 1.19 & 0.55 & 1.83 & 1 & II \\
\hline $\begin{array}{l}\text { Pregabalin or } \\
\text { duloxetine/ } \\
\text { combination of both } \\
\text { drugs }\end{array}$ & -0.10 & -0.33 & 0.13 & 1 & II \\
\hline Lacosamide/placebo ${ }^{b}$ & 0.28 & 0.15 & 0.41 & 2 & II \\
\hline Metanx/placebo & -0.43 & -0.86 & 0.001 & 1 & II \\
\hline Mirogabalin/placebob & 0.31 & 0.07 & 0.55 & 1 & II \\
\hline $\begin{array}{l}\text { Mirogabalin/ } \\
\text { pregabalin }^{\mathbf{b}}\end{array}$ & 0.40 & 0.08 & 0.72 & 1 & II \\
\hline Nabilone/placebob & 1.32 & 0.52 & 2.13 & 1 & I \\
\hline Nitrosense/placebo ${ }^{b}$ & 0.59 & 0.03 & 1.15 & 1 & II \\
\hline $\begin{array}{l}\text { Nutmeg extract/ } \\
\text { placebo }\end{array}$ & -0.01 & -0.46 & 0.44 & 1 & II \\
\hline $\begin{array}{l}\text { PF-05089771/ } \\
\text { placebo }\end{array}$ & 0.34 & -0.10 & 0.77 & 1 & I \\
\hline
\end{tabular}

\begin{tabular}{|c|c|c|c|c|c|}
\hline Comparison & $S M D^{a}$ & LCL & UCL & $\begin{array}{l}\text { Number } \\
\text { of articles }\end{array}$ & Class \\
\hline Pregabalin/placebo ${ }^{b}$ & 0.32 & 0.14 & 0.50 & 14 & I and || \\
\hline $\begin{array}{l}\text { Pregabalin/ } \\
\text { venlafaxine }^{\text {b }}\end{array}$ & 0.84 & 0.48 & 1.20 & 1 & I \\
\hline $\begin{array}{l}\text { Pregabalin/ } \\
\text { carbamazepine }^{\text {b }}\end{array}$ & 0.86 & 0.50 & 1.21 & 1 & I \\
\hline $\begin{array}{l}\text { Pregabalin and } \\
\mathrm{N} \text {-acetylcysteine/ } \\
\text { pregabalin alone }^{\mathrm{b}}\end{array}$ & 1.00 & 0.56 & 1.44 & 1 & ॥ \\
\hline Tanezumab/placebo ${ }^{\text {b }}$ & 0.47 & 0.001 & 0.93 & 1 & $\|$ \\
\hline Tapentadol/placebo ${ }^{\text {b }}$ & 0.78 & 0.54 & 1.03 & 1 & $\|$ \\
\hline Tocotrienols/placebo & 0.09 & -0.14 & 0.32 & 1 & ॥ \\
\hline Clonidine/placebo & 0.29 & -0.01 & 0.58 & 1 & $\|$ \\
\hline Valproic acid/placebo ${ }^{\text {b }}$ & 0.86 & 0.38 & 1.33 & 3 & $\|$ \\
\hline $\begin{array}{l}\text { Venlafaxine/ } \\
\text { carbamazepine }\end{array}$ & -0.02 & -0.32 & 0.35 & 1 & I \\
\hline
\end{tabular}

Abbreviations: $L C L=$ lower confidence limit; $S M D=$ standardized mean difference; SNRI = serotonin-norepinephrine reuptake inhibitor; TCA = tricyclic antidepressants; $\mathrm{UCL}=$ upper confidence limit.

a SMD $>0$ indicates intervention is clinically better than comparator.

${ }^{\mathrm{b}} p<0.05$.

c Placebo more efficacious.

likely than placebo to improve pain (SMD 0.01; 95\% CI, -0.47 to 0.48 ; very low confidence; 1 Class II study).

There is insufficient evidence to determine whether dextromethorphan/quinidine is more or less likely than placebo to improve pain (SMD 0.69; $95 \% \mathrm{CI},-0.03$ to 1.41 ; very low confidence; 1 Class II study). The reason for insufficient evidence is that there was only 1 Class II study with a large CI.

AZD2423 is possibly less likely than placebo to improve pain (SMD -0.45 ; $95 \%$ CI, -0.87 to 0.04 ; low confidence; 1 Class II study).

\section{Comparative Effectiveness Studies: Oral Medications}

Pregabalin is probably more likely than carbamazepine to improve pain (SMD 0.86; 95\% CI, 0.50-1.21; large effect, moderate confidence; 1 Class I study).

Venlafaxine is probably no more likely than carbamazepine to improve pain (SMD -0.02; 95\% CI, -0.32 to 0.35 ; moderate confidence; 1 Class I and 1 Class II study).

There is insufficient evidence to determine whether mirogabalin is more or less likely than pregabalin to improve pain (SMD 0.23; $95 \% \mathrm{CI},-0.05$ to 0.52 ; very low confidence; 1 Class II study).

Pregabalin is probably more likely than venlafaxine to improve pain (SMD 0.84; 95\% CI, 0.48-1.20; large effect, moderate confidence; 1 Class I study). 
Table 3 Efficacy of Oral Medications for Painful Diabetic Neuropathy by Class Effect

\begin{tabular}{llllllll}
\hline Medication class & SMD $^{\mathbf{a}}$ & LCL & UCL & $\begin{array}{l}\text { Number of } \\
\text { articles }\end{array}$ & $\begin{array}{l}\text { Number of } \\
\text { patients }\end{array}$ & Conclusion & Confidence \\
\hline Gabapentinoids & 0.44 & 0.25 & 0.63 & 16 & 3,550 & Probably more likely than placebo to improve pain & Moderate \\
\hline $\begin{array}{l}\text { Sodium channel } \\
\text { blocker }\end{array}$ & 0.56 & 0.25 & 0.87 & 5 & 566 & Probably more likely than placebo to improve pain & Moderate \\
\hline SNRI & 0.47 & 0.34 & 0.60 & 9 & 1,884 & Probably more likely than placebo to improve pain & Moderate \\
\hline SNRI-opioid & 0.62 & 0.38 & 0.86 & 4 & 775 & Probably more likely than placebo to improve pain & Moderate \\
\hline TCA & 0.95 & 0.15 & 1.75 & 3 & 139 & Possibly more likely than placebo to improve pain Low \\
\hline
\end{tabular}

Abbreviations: $L C L=$ lower confidence limit; SMD = standardized mean difference; SNRI = serotonin-norepinephrine reuptake inhibitor; $T C A=$ tricyclic antidepressants; $\mathrm{UCL}=$ upper confidence limit.

a $\mathrm{SMD}>0$ indicates intervention is clinically better than placebo.

Amitriptyline is possibly no more likely than gabapentin to improve pain (SMD 0.33; $95 \% \mathrm{CI},-0.32$ to 0.98 ; low confidence; 1 Class II study).

The combination of duloxetine $(60 \mathrm{mg} / \mathrm{d})$ and pregabalin $(300 \mathrm{mg} / \mathrm{d})$ is possibly no more likely than either high-dose duloxetine $(120 \mathrm{mg} / \mathrm{d})$ or high-dose pregabalin $(600 \mathrm{mg} / \mathrm{d})$ to improve pain (SMD -0.10 ; $95 \% \mathrm{CI},-0.33$ to 0.13 ; low confidence, 1 Class II study).

Duloxetine is possibly more likely than nortriptyline to improve pain (SMD 1.64; 95\% CI, 0.63-2.65; large effect, low confidence; 1 Class II study).

Pregabalin and $\mathrm{N}$-acetylcysteine is possibly more likely than pregabalin alone to improve pain (SMD 1.00; 95\% CI, 0.56-1.44; large effect, low confidence; 1 Class II study).

$\gamma$-linolenic acid is possibly no more likely than $\alpha$-lipoic acid to improve pain (SMD 0.34; 95\% CI, -0.12 to 0.80 ; low confidence; 1 Class II study).

Epalrestat sustained release is possibly no more likely than epalrestat immediate release to improve pain (SMD 0.25; $95 \%$ CI, -0.14 to 0.64 ; low confidence; 1 Class II study).

\section{Combination Studies}

The combination of valproic acid and glyceryl trinitrate is possibly more likely than placebo to improve pain (SMD 1.14; 95\% CI, 0.52-1.77; large effect, low confidence; 1 Class II study).

\section{Topical Medications}

In people with painful diabetic polyneuropathy, what is the efficacy of using topical pharmacologic interventions to reduce pain compared with placebo or an active comparator?

Capsaicin is possibly more likely than placebo to improve pain (SMD 0.30; 95\% CI, 0.14-0.47; small effect, low confidence; 1 Class I study of $8 \%$ and 1 Class II study of 0.075\%).
Nitrosense patch is possibly more likely than placebo to improve pain (SMD 0.59; 95\% CI, 0.03-1.15; medium effect, low confidence; 1 Class II study).

Citrullus colocynthis is possibly more likely than placebo to improve pain (SMD 0.91; 95\% CI, 0.36-1.45; large effect, low confidence; 1 Class II study).

Glyceryl trinitrate spray is possibly more likely than placebo to improve pain (SMD 1.19; 95\% CI, 0.55-1.83; large effect, low confidence; 1 Class II study).

Topical clonidine is possibly no more likely than placebo to improve pain (SMD 0.29; $95 \% \mathrm{CI},-0.01$ to 0.58 ); low confidence; 1 Class II study).

Buprenorphine transdermal patches are possibly no more likely than placebo to improve pain (SMD 0.23; 95\% CI, -0.09 to 0.55 ; low confidence; 1 Class II study).

\section{Subgroup Analysis for All Medications Combined}

\section{Age}

Metaregression revealed no significant association between age and pain reduction (slope for age; SMD 0.001; 95\% CI, -0.10 to 0.11 ).

\section{Sex}

Metaregression revealed no significant association between sex and pain reduction (slope for proportion male sex; SMD $0.01 ; 95 \% \mathrm{CI},-0.02$ to 0.05 ).

\section{Practice Recommendations}

\section{Recommendation 1 Rationale}

Painful peripheral neuropathy is a common complication of diabetes and is more common in patients with longer duration of diabetes and poor glycemic control. ${ }^{34-36}$ Patients with diabetes should be assessed for the presence of peripheral neuropathy and neuropathic pain periodically, 


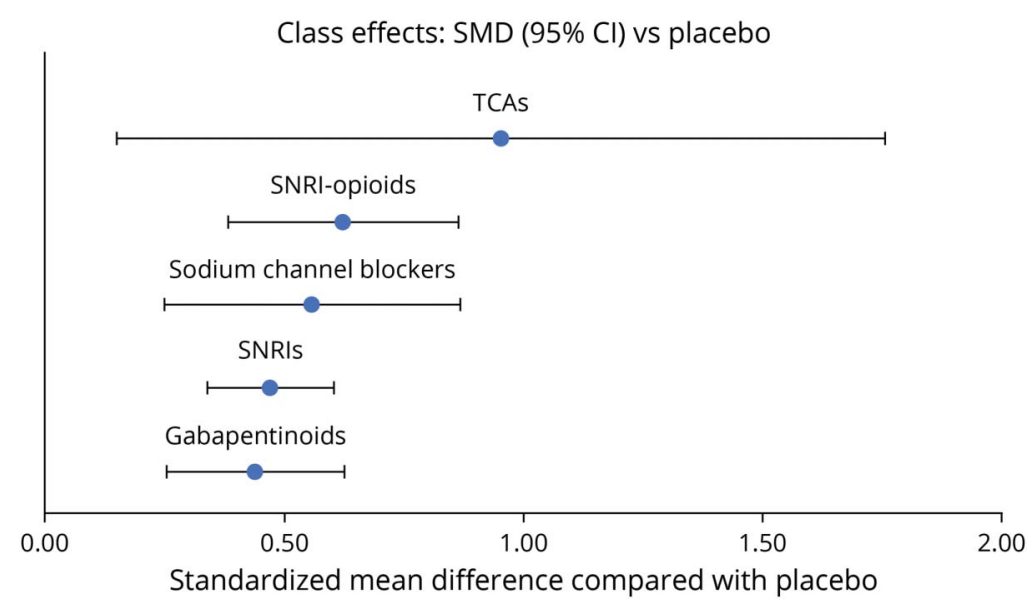

The effects of different oral medication classes on painful diabetic neuropathy including gabapentinoids, serotoninnorepinephrine reuptake inhibitors (SNRIs), sodium channel blockers, SNRI/opioid dual mechanism agents, and tricyclic antidepressants (TCAs). CI = confidence interval; SMD = standardized mean difference. although the optimal frequency of such assessment is not clear. Most studies of treatments for painful diabetic peripheral neuropathy have assessed pain using visual analog scales, numerical rating scales, or similar measures. Such scales are commonly used in practice, but they do not provide insight into the effect of pain on patients' functioning and well-being. Other scales that assess pain interference (Brief Pain Inventory-Diabetic Peripheral Neuropathy) ${ }^{37}$ or effects on quality of life (Norfolk Quality of Life-Diabetic Neuropathy) ${ }^{38}$ may provide more relevant information to assess the need for treatment and success of such treatment.

\section{Recommendation Statement 1}

Clinicians should assess patients with diabetes for peripheral neuropathic pain and its effect on these patients' function and quality of life (Level B).

\section{Recommendation 2 Rationale}

Several classes of pharmacologic agents have been demonstrated to reduce pain in patients with PDN. However, complete resolution of symptoms is often not achieved. Patients expect a high degree of pain relief, and many expect complete pain resolution. ${ }^{39}$ In order to promote patient satisfaction, aligning patients' expectations with the expected efficacy of interventions (approximately 30\% pain reduction is considered a success in clinical trials) would be beneficial.

\section{Recommendation Statement 2}

When initiating pharmacologic intervention for PDN, clinicians should counsel patients that the goal of therapy is to reduce, and not necessarily to eliminate, pain (Level B).

\section{Recommendation 3 Rationale}

In treating patients with PDN, it is important to assess other factors that may also affect pain perception and quality of life. Patients with diabetes are more likely to have mood disorders (most commonly, major depression) and sleep disorders (especially obstructive sleep apnea) than the general population. ${ }^{40,41}$ Mood and sleep can both influence pain perception. ${ }^{42,43}$ Therefore, treating concurrent mood and sleep disorders may help reduce pain and improve quality of life, apart from any direct treatment of the painful neuropathy. Some treatments for painful neuropathy may also have beneficial effects on mood and sleep (e.g., TCAs and SNRIs) and, therefore, may produce some of their benefits through these pathways.

\section{Recommendation Statement 3}

Clinicians should assess patients with PDN for the presence of concurrent mood and sleep disorders and treat them as appropriate (Level B).

\section{Recommendation 4 Rationale}

PDN is a highly prevalent condition that greatly affects quality of life. ${ }^{6}$ Four classes of oral medications have demonstrated evidence of pain reduction in meta-analyses: TCAs, SNRIs, gabapentinoids, and sodium channel blockers. The best estimates of the effect sizes and the corresponding CIs are comparable for all of these drug classes, which makes recommendations for one over another difficult.

\section{Recommendation Statement 4}

In patients with PDN, clinicians should offer TCAs, SNRIs, gabapentinoids, and/or sodium channel blockers to reduce pain (Level B).

\section{Recommendation 5 Rationale}

Some patients prefer topical, nontraditional, or nonpharmacologic interventions; therefore, it is important to be able to offer interventions that fit with these patient preferences. Furthermore, given the downsides of opioid therapy, ${ }^{8,9}$ the ability to offer effective nonopioid interventions to reduce pain in patients failing initial therapies is important. TCAs, SNRIs, gabapentinoids, and sodium channel blockers have all 
been shown to improve pain in patients with diabetic neuropathy. While other interventions have been less well studied, at least 1 randomized controlled trial supports the use of other interventions, such as topical (capsaicin, glyceryl trinitrate spray, Citrullus colocynthis), nontraditional (Ginkgo biloba), and nonpharmacologic approaches (exercise, cognitive behavioral therapy, mindfulness). ${ }^{44}$ Furthermore, there is moderate and consistent evidence for the use of cognitive behavioral therapy (CBT) for many types of chronic pain. ${ }^{45,46}$ In addition, while direct evidence on efficacy for CBT for painful neuropathy is not yet robust, there is promising pilot evidence for the use of CBT for some types of neuropathic pain. $^{47,48}$

\section{Recommendation Statement 5a}

Clinicians may assess patient preferences for effective oral, topical, nontraditional, and nonpharmacologic interventions for PDN (Level C).

\section{Recommendation Statement 5b}

In patients preferring topical, nontraditional, or nonpharmacologic interventions, providers may offer topical (capsaicin, glyceryl trinitrate spray, Citrullus colocynthis), nontraditional (Ginkgo biloba), or nonpharmacologic interventions (CBT, exercise, Tai Chi, mindfulness) (Level C).

\section{Recommendation 6 Rationale}

Individual pharmacologic agents from the TCA, SNRI, gabapentinoid, and sodium channel blocker classes have similar efficacy on neuropathic pain outcomes. However, class and agent-specific differences exist in the potential for and nature of adverse effects. For example, the potential anticholinergic side effects of TCAs may be less tolerated in patients with preexisting constipation, urinary retention, or orthostatic hypotension. Similarly, the potential side effects of SNRIs and sodium channel blockers, such as nausea, fatigue, and dizziness, may be less well-tolerated in patients with similar preexisting symptoms. Given that gabapentinoids can lead to peripheral edema, these medications should be used cautiously in patients with peripheral edema from comorbidities such as cardiac, renal, or liver disease. Valproic acid has potential teratogenic effects such as neural tube defects as well as hepatotoxicity, pancreatitis, hyponatremia, pancytopenia, and many other serious adverse events. ${ }^{49}$ Dose adjustment for the level of renal function is required for many of these agents and must be reviewed before prescribing. Discussion of cost and patient preference should be made. Furthermore, patient comorbidities such as depression/anxiety (TCAs and SNRIs) and seizures (gabapentinoids and sodium channel blockers) may make certain therapeutic classes more appropriate given dual indications.

\section{Recommendation Statement 6a}

Given similar efficacy, clinicians should consider factors other than efficacy, including potential adverse effects, patient comorbidities, cost, and patient preferences, when recommending treatment for PDN (Level B).

\section{Recommendation Statement $\mathbf{6 b}$}

In patients of childbearing potential with $\mathrm{PDN}$, clinicians should not offer valproic acid (Level B).

\section{Recommendation Statement 6c}

In all patients with PDN, clinicians should not prescribe valproic acid given the potential for serious adverse events unless multiple other effective medications have failed (Level B).

\section{Recommendation 7 Rationale}

A series of medications may need to be tried to identify the treatment that most benefits a given patient with PDN. A treatment to reduce neuropathic pain in a patient should be considered ineffective when that medication has been titrated to a demonstrated effective dose and duration (Table 1) without significant pain reduction. The typical duration of treatment in which efficacy is demonstrated is approximately 12 weeks, with a range from 4 to 16 weeks. A treatment to reduce neuropathic pain in a patient should be considered intolerable when that medication causes adverse effects that outweigh any benefit in reduced neuropathic pain. While the exact side effect profile is dependent on the individual medication, dizziness, somnolence, and fatigue have been demonstrated with each class of oral medication, and application site reactions have been demonstrated with each topical medication. An intervention to relieve neuropathic pain should be considered a failure for an individual patient when it is either ineffective after 12 weeks or intolerable. Failure with 1 intervention does not preclude a good response, without side effects, to an alternative intervention from the same class or a different class. Choosing a different mechanism of action (class of medication) is expected to increase the likelihood of achieving pain relief or avoiding the side effects encountered with the initial intervention. If only partial efficacy is achieved, adding a second medication of a different class may provide combined efficacy greater than that provided by each medication individually.

\section{Recommendation Statement 7a}

Clinicians should counsel patients that a series of medications may need to be tried to identify the treatment that most benefits patients with PDN (Level B).

\section{Recommendation Statement 7b}

Clinicians should determine that an individual intervention to reduce neuropathic pain is a failure either when the medication has been titrated to a demonstrated efficacious dose for approximately 12 weeks without clinically significant pain reduction or when side effects from the medication outweigh any benefit in reduced neuropathic pain (Level B).

\section{Recommendation Statement 7c}

Clinicians should offer patients a trial of a medication from a different effective class when they do not achieve meaningful improvement or if they experience significant adverse effects with the initial therapeutic class (Level B).

\section{Recommendation Statement 7d}

For patients who achieve partial improvement with an initial therapeutic class, clinicians should offer a trial of a medication 
from a different effective class or combination therapy by adding a medication from a different effective class (Level B).

\section{Recommendation 8 Rationale}

The use of opioids for chronic, noncancer pain has been strongly discouraged in a position paper published by the American Academy of Neurology in 2014 and a systematic review by the Centers for Disease Control and Prevention primarily because of weak to nonexistent evidence of longterm efficacy and the likelihood of severe long-term adverse consequences. ${ }^{8,9}$ The lack of long-term efficacy in association with a very poor risk profile has been subsequently reported in a systematic review from the NIH. This study concluded that "Evidence is insufficient to determine the effectiveness of long-term opioid therapy for improving chronic pain and function. Evidence supports a dose-dependent risk for serious harms." ${ }^{50}$ A 1-year trial of opioids for moderate to severe low back or hip or knee osteoarthritis pain reported that opioids were nonsuperior to nonopioid medications. ${ }^{51}$ The most important long-term adverse consequences include nearly universal dependence, high rates of more severe dependence and opioid use disorder, morbidity via overdose events, and excess mortality. ${ }^{8,9,46,52}$ Data from the CDC suggest that it is likely that dependence may set in within days to weeks of starting opioids. ${ }^{53}$ Severe events are underreported in randomized trials largely because of the relative rarity of these events, enriched recruitment methods, and the brief duration of most of these trials. Although the most severe adverse outcomes are dose-related, overdose events can occur with intermittent and nonchronic use as well, especially when opioids are combined with sedative hypnotics, which is common. ${ }^{54}$ Whereas short-term pain reduction has been demonstrated in patients with PDN with opioids, no randomized trial of opioids over a long duration has demonstrated clinically meaningful improvement of pain and function, which would be needed to justify the severity of potential side effects. ${ }^{50}$

\section{Recommendation Statement 8a}

Clinicians should not use opioids for the treatment of PDN (Level B).

\section{Recommendation Statement $\mathbf{8 b}$}

If patients are currently on opioids for the treatment of PDN, clinicians may offer the option of a safe taper off these medications and discuss alternative nonopioid treatment strategies (Level C).

\section{Recommendation 9 Rationale}

Tramadol was originally approved and marketed as less opioid-like and therefore less risky. It was classified as a Schedule IV drug by the Drug Enforcement Administration (DEA), and until recently, it was not included in most state prescription drug monitoring programs. However, the risk profile of tramadol is also poor, with respiratory depression, addiction, and overdose reflected in a Food and Drug Administration (FDA) black box warning. ${ }^{55}$ A recent study reported an increase in all-cause mortality among patients taking tramadol for osteoarthritis. ${ }^{56}$ Although true prevalence is unknown, serotonin syndrome has also been associated with tramadol. ${ }^{57}$ The abuse liability in terms of reported abuse events per population is substantial and greater than that for morphine. ${ }^{58}$

Tapentadol is also associated with severe adverse events, as specified in an FDA black box warning, including lifethreatening respiratory depression, addiction, overdose, and death. ${ }^{59}$ Tapentadol is a Schedule II opioid (DEA classification), similar to other potent opioids. Its abuse potential, measured as abuse events per dispensed prescription, is higher than that of hydrocodone. ${ }^{58}$ The efficacy of tramadol and tapentadol for painful neuropathy is only reported in studies of short duration. ${ }^{60}$ Demonstration of long-term efficacy without substantial side effects would be needed to justify the severity of potential side effects.

\section{Recommendation Statement 9a}

Clinicians should not use tramadol and tapentadol (opioids/ SNRI dual mechanism agents) for the treatment of PDN (Level C).

\section{Recommendation Statement 9b}

If patients are currently on tramadol and tapentadol (opioids/ SNRI dual mechanism agents) for the treatment of PDN, clinicians may offer the option of a safe taper off these medications and discuss alternative nonopioid treatment strategies (Level C).

\section{Suggestions for Future Research}

Our review highlights key gaps in current knowledge that should be addressed in future studies. Specifically, few studies have investigated the effect of interventions on quality of life, patient functioning, mood, or sleep. Furthermore, few comparative effectiveness studies have been performed. Those studies with an active comparator have rarely included more than one other intervention; therefore, there are limited data to support one therapeutic intervention over another. One exception is the PAIN-CONTRoLS study, which compared 4 active medications for patients with cryptogenic neuropathy. ${ }^{61}$ The study found that duloxetine and nortriptyline outperformed pregabalin and mexiletine. Comparable studies in PDN are also needed. Similarly, evidence for combination therapy compared with monotherapy and for the best titration schedule is limited. Another limitation to the current evidence is the lack of data beyond 16 weeks for any intervention. Given the chronicity of pain in those with diabetic neuropathy and the potential for evolving side effects, longterm studies are needed to better inform the long-term pain management in this population. Specifically, future studies should focus on the long-term effects (positive and negative) of opioids in this population to determine whether there is any role for these medications in this population. In addition, 
few studies exist that compare different modalities of treatment, such as oral medications, topical treatments, nontraditional therapies, and nonpharmacologic interventions. Finally, no information is available to predict which patients will respond best to specific interventions. However, groups are trying to employ pain phenotyping to see if a differential response exists. The ability to target effective interventions to the right subgroup has the potential to improve pain management in those with diabetic neuropathy, but limited data are available to guide these choices. We also lumped medications within one class together, but it is possible that certain medications within a class are better than others. Patients with PDN have multiple effective interventions available to them, but new studies should address our gaps in knowledge to enable better treatments for the future.

\section{Disclaimer}

Clinical practice guidelines, practice advisories, systematic reviews, and other guidance published by the American Academy of Neurology (AAN) and its affiliates are assessments of current scientific and clinical information provided as an educational service. The information (1) should not be considered inclusive of all proper treatments methods of care, or as a statement of the standard of care; (2) is not continually updated and may not reflect the most recent evidence (new evidence may emerge between the time information is developed and when it is published or read); (3) addresses only the question(s) specifically identified; (4) does not mandate any particular course of medical care; and (5) is not intended to substitute for the independent professional judgment of the treating provider, as the information does not account for individual variation among patients. In all cases, the selected course of action should be considered by the treating provider in the context of treating the individual patient. Use of the information is voluntary. The AAN provides this information on an "as is" basis and makes no warranty, expressed or implied, regarding the information. The AAN specifically disclaims any warranties of merchantability or fitness for a particular use or purpose. AAN assumes no responsibility for any injury or damage to persons or property arising out of or related to any use of this information or for any errors or omissions.

\section{Conflict of Interest}

The American Academy of Neurology (AAN) is committed to producing independent, critical, and trustworthy clinical practice guidelines and evidence-based documents. Significant efforts are made to minimize the potential for conflicts of interest to influence the recommendations of this evidencebased document. Management and disclosure of document developer relationships is conducted in compliance with the 2017 AAN process manual section titled "Implementing the AAN Conflict of Interest Policy for Guidelines and Case Definitions," which can be viewed at aan.com.

\section{Acknowledgment}

The authors thank Tuan Anh Lee, DPM, Chief of Podiatry Service, Kaiser Permanente, Los Angeles Medical Center, for early contributions to the development of this guideline.

\section{Study Funding}

This guideline was developed with financial support from the American Academy of Neurology (AAN). Authors who serve as AAN subcommittee members or as methodologists (B.C.C., G.G., J.H., N.L., A.R.-G., D.S.), or who are or were AAN employees (M.D.O., S.R.W.), were reimbursed by the AAN for expenses related to travel to subcommittee meetings where drafts of manuscripts were reviewed.

\section{Disclosure}

R. Price has received honoraria for a collaboration between Critical Thinking and Grifols; serves as codirector of and has received honoraria for organization and lecturing for a Penn Neurology Board Review Course; and has given expert testimony in 2 cases regarding etiology, diagnosis, and management of foot pain, sensory loss, and weakness. D. Smith is a paid evidence-based medicine consultant for the AAN. G. Franklin serves on a scientific advisory board for Workers' Compensation Research Institute, serves as an editorial board member for Neuroepidemiology, serves as a reviewer for $\mathrm{Neu}$ rology, serves on the editorial board for Evidence Review, and has received research funding from CDC, Patient-Centered Outcomes Research Institute (PCORI), Washington State Department of Labor, and Mathematica. G. Gronseth has received travel funding from the AAN to attend Guidelines Subcommittee meetings, serves as an associate editor for Neurology, has served as chief evidence-based medicine consultant for the AAN, and serves as an editorial advisory board member of Brain \& Life. M. Pignone has received funding for travel from the Familial Hypercholesterolemia Foundation; royalties from publishing chapters in Current Medical Diagnosis \& Treatment and Up To Date; and research support from Cancer Prevention Research Institute of Texas, Healthwise, the Agency for Healthcare Research and Quality, American Cancer Society, National Cancer Institute, Verily, and the National Institute of Diabetes and Digestive and Kidney Diseases (NIDDK). W. David has received royalties for a continuing medical education (CME) video course on EMG/neuromuscular medicine, performs EMG in practice, and has served as a consultant for Flex Pharma. C. Armon serves as associate editor for Journal of the Neurologic Sciences; has received royalties from publishing from UpToDate and Medscape; has provided expert testimony in personal injury and medical-legal cases; and has acted as a neurology consultant for Inbal, Inc. (the Israeli Government Insurance Agency). B. Perkins has received honoraria from Insulet for a $\mathrm{CME}$ webinar; has received honoraria for $\mathrm{CME}$ events from Abbott, Novo Nordisk, Medtronic, Janssen, Dexcom, and Boehringer Ingelheim; has received research support from Boehringer Ingelheim, the Bank of Montreal, NIDDK, Juvenile Diabetes Research Foundation, Diabetes Canada, 
Canadian Institutes of Health Research; and has served on scientific advisory boards for Insulet, Abbott, Novo Nordisk, and Boehringer Ingelheim. V. Bril serves on scientific advisory boards for CSL Behring, USB, and Pfizer; has received honoraria from CSL Behring, USB, and Pfizer; has received research support from UCB, Grifols, CSL Behring, Octapharma, Argenx, Muscular Dystrophy Canada, CIDP/GBS Foundation, Myasthenia Gravis Foundation of America, and the NIDDK; and has participated in the development of an American Diabetes Association position statement on PDN and of a Canadian Diabetes Association clinical practice guideline on diabetic neuropathy. A. Rae-Grant has received publishing royalties from 2 publications relating to health care and has received travel funding from the AAN to attend Guidelines Subcommittee meetings. J. Halperin has received personal compensation for serving as an employee of Atlantic Health System, received personal compensation in the range of \$500-\$4,999 for serving as an Expert Witness for Tri-Century Insurance Company, received personal compensation in the range of $\$ 0-\$ 499$ for serving as a medical consultant with TelaDoc, and received intellectual property interests from a publication relating to health care. The institution of Dr. Halperin has received research support from NIH. N. Licking has received travel funding from the AAN to attend Guidelines Subcommittee meetings. M. Dolan O'Brien is an employee of the AAN. S. Wessels is an employee of the AAN. L. MacGregor has received honoraria From PCORI and Partners HealthCare. K. Fink serves on the American Academy of Family Physician's Commission on Health of the Public \& Science (AAFP CHPS), funding for travel to attend AAFP CHPS meetings, and compensation for consulting services that are typically related to Medicaid. L. Harkless has served on scientific advisory boards for Genentech and Next Science; has received honoraria from Genentech, NextScience, and the Texas Podiatric Medical Society; holds stock in Metric Medical and Mr3Health; has received funding from the International Diabetes Foundation and honoraria from Mississippi Podiatric Medical Society and North Carolina Podiatric Medical Society; has given expert deposition on a nonhealing wound; and has given expert opinion on a medical record regarding diabetes. $\mathrm{L}$. Colbert reports no disclosures relevant to the manuscript. B. Callaghan has received personal compensation for serving as an employee of University of Michigan, personal compensation for serving as an employee of Ann Arbor Veterans Affairs, personal compensation in the range of $\$ 500-\$ 4,999$ for serving as a Consultant for Dynamed, personal compensation in the range of \$500-\$4,999 for serving as an Editor, Associate Editor, or Editorial Advisory Board Member for AAN, personal compensation in the range of $\$ 10,000-\$ 49,999$ for serving as an expert witness for medical-legal work, personal compensation in the range of $\$ 50,000-\$ 99,999$ for serving as an expert witness for Vaccine Injury Compensation Program, and personal compensation in the range of \$500-\$4,999 for serving as a grant reviewer with NIH. The institution of Dr. Callaghan has received research support from AAN, JDRF, NIDDK, and VA Clinical Science Research and Development. Go to Neurology. org/N for full disclosures.

\section{Publication History}

Received by Neurology June 29, 2021. Accepted in final form October 15, 2021.

Appendix Authors

\begin{tabular}{lll}
\hline Name & Location & Contribution \\
\hline $\begin{array}{ll}\text { Raymond } \\
\text { Price, MD }\end{array}$ & $\begin{array}{l}\text { Department of Neurology, } \\
\text { University of Pennsylvania, }\end{array}$ & $\begin{array}{l}\text { Study concept and design; } \\
\text { analysis or interpretation } \\
\text { Philadelphia }\end{array}$ \\
& $\begin{array}{l}\text { of data; drafting/revising } \\
\text { the manuscript; and critical } \\
\text { revision of the manuscript } \\
\text { for important intellectual } \\
\end{array}$ \\
& content
\end{tabular}

\begin{tabular}{lll}
\hline Don Smith, & Department of Neurology, & Study concept and design; \\
MD & University of Colorado, & acquisition of data; \\
Aurora & analysis or interpretation \\
& of data; drafting/revising \\
& the manuscript; and critical \\
& revision of the manuscript \\
& for important intellectual \\
& content
\end{tabular}

\begin{tabular}{lll}
\hline Gary & Department of Neurology, & Acquisition of data; \\
Franklin, MD, University of Washington, & analysis or interpretation \\
MPH & Seattle & $\begin{array}{l}\text { of data; and critical } \\
\text { revision of the manuscript } \\
\end{array}$ \\
& for important intellectual \\
& content
\end{tabular}

\begin{tabular}{lll}
\hline Gary & Department of Neurology, & Analysis or interpretation \\
Gronseth, & University of Kansas Medical & of data; and critical \\
MD & Center, Kansas City & $\begin{array}{l}\text { revision of the manuscript } \\
\text { for important intellectual } \\
\text { content }\end{array}$ \\
& & \\
\hline
\end{tabular}

\begin{tabular}{lll}
\hline Michael & Department of Internal & $\begin{array}{l}\text { Study concept and design; } \\
\text { Pignone, MD, }\end{array}$ \\
MPH & $\begin{array}{l}\text { Medicine, The University of at Austin Dell Medical } \\
\text { Texalysis or interpretation } \\
\text { of data; and critical }\end{array}$ \\
& $\begin{array}{l}\text { revision of the manuscript } \\
\text { for important intellectual } \\
\text { content }\end{array}$
\end{tabular}

William S. Department of Neurology, Study concept and design;

David, MD, Massachusetts General analysis or interpretation

PhD Hospital, Boston of data; and critical revision of the manuscript for important intellectual content

Carmel Department of Neurology, Tel Study concept and design;
Armon, MD, Aviv University Sackler School analysis or interpretation MSc, MHS of Medicine and Shamir (Assaf of data; and critical Harofeh) Medical Center, revision of the manuscript Israel for important intellectual content

\begin{tabular}{lll}
\hline Bruce A. & Leadership Sinai Centre for & Study concept and design; \\
Perkins, MD, & Diabetes, Sinai Health & analysis or interpretation \\
MPH & System, University of Toronto, & of data; and critical \\
Canada & $\begin{array}{l}\text { revision of the manuscript } \\
\text { for important intellectual } \\
\text { content }\end{array}$
\end{tabular}

Vera Bril, MD Division of Neurology, Department of Medicine, Toronto General Hospital, Study concept and design; analysis or interpretation of data; and critical revision of the manuscript for important intellectual content

\begin{tabular}{lll}
\hline Alexander & Professor Emeritus, & Analysis or interpretation \\
Rae-Grant, & Cleveland Clinic Lerner & of data; and critical \\
MD & College of Medicine of Case & revision of the manuscript \\
& Western Reserve University, & for important intellectual \\
& OH & content
\end{tabular}


Appendix (continued)

\begin{tabular}{lll}
\hline Name & Location & Contribution \\
\hline $\begin{array}{lll}\text { John } \\
\text { Halperin, MD }\end{array}$ & $\begin{array}{l}\text { Department of } \\
\text { Neurosciences, Overlook } \\
\text { Medical Center, Summit, NJ }\end{array}$ & $\begin{array}{l}\text { Analysis or interpretation } \\
\text { of data; and critical } \\
\text { revision of the manuscript } \\
\text { for important intellectual } \\
\text { content }\end{array}$ \\
& & int
\end{tabular}

Nicole New West Physicians, Golden, Analysis or interpretation Licking, DO CO of data; and critical revision of the manuscript for important intellectual content

\begin{tabular}{lll}
\hline Mary Dolan & American Academy of & Critical revision of the \\
O'Brien, MLIS Neurology, Minneapolis, MN & $\begin{array}{l}\text { manuscript for important } \\
\text { intellectual content }\end{array}$
\end{tabular}

\begin{tabular}{lll}
\hline Scott R. & American Academy of & $\begin{array}{l}\text { Critical revision of the } \\
\text { Wessels, }\end{array}$ \\
MPS, ELS & Neurology, Minneapolis, MN & $\begin{array}{l}\text { inuscript for important } \\
\text { intellectual content }\end{array}$
\end{tabular}

Leslie C. Neuropathy Action Analysis or interpretation

MacGregor, Foundation, Santa Ana, CA of data; critical revision of PhD, VMD, JD

the manuscript for important intellectual content

\begin{tabular}{ll}
\hline Kenneth & Kamehameha Schools, \\
Fink, MD, & Honolulu, HI \\
MPH &
\end{tabular}

Analysis or interpretation of data; critical revision of the manuscript for important intellectual content

\begin{tabular}{ll}
\hline Lawrence B. & University of Texas Rio \\
Harkless, & Grande Valley School of \\
DPM & Podiatric Medicine, Edinbu
\end{tabular}

Analysis or interpretation of data; critical revision of the manuscript for important intellectual content

\begin{tabular}{|c|c|c|}
\hline $\begin{array}{l}\text { Lindsay } \\
\text { Colbert, MA }\end{array}$ & $\begin{array}{l}\text { The Foundation for Peripheral } \\
\text { Neuropathy, Buffalo Grove, IL }\end{array}$ & $\begin{array}{l}\text { Analysis or interpretation } \\
\text { of data; critical revision of } \\
\text { the manuscript for } \\
\text { important intellectual } \\
\text { content }\end{array}$ \\
\hline $\begin{array}{l}\text { Brian C. } \\
\text { Callaghan, } \\
\text { MD, MS }\end{array}$ & $\begin{array}{l}\text { Department of Neurology, } \\
\text { University of Michigan, Ann } \\
\text { Arbor }\end{array}$ & $\begin{array}{l}\text { Study concept and design; } \\
\text { acquisition of data; } \\
\text { analysis or interpretation } \\
\text { of data; drafting/revising } \\
\text { the manuscript; and critical } \\
\text { revision of the manuscript } \\
\text { for important intellectual } \\
\text { content }\end{array}$ \\
\hline
\end{tabular}

\section{References}

1. Callaghan BC, Kerber KA, Lisabeth LL, et al. Role of neurologists and diagnostic tests on the management of distal symmetric polyneuropathy. JAMA Neurol. 2014;71(9): 1143-1149.

2. Johannsen L, Smith T, Havsager AM, et al. Evaluation of patients with symptoms suggestive of chronic polyneuropathy. J Clin Neuromuscul Dis. 2001;3(2):47-52.

3. Kanji JN, Anglin RE, Hunt DL, Panju A. Does this patient with diabetes have largefiber peripheral neuropathy? JAMA. 2010;303(15):1526-1532.

4. Lubec D, Müllbacher W, Finsterer J, Mamoli B. Diagnostic work-up in peripheral neuropathy: an analysis of 171 cases. Postgrad Med J. 1999;75(890):723-727.

5. Daousi C, MacFarlane IA, Woodward A, Nurmikko TJ, Bundred PE, Benbow SJ. Chronic painful peripheral neuropathy in an urban community: a controlled comparison of people with and without diabetes. Diabet Med. 2004;21(9):976-982.

6. Van Acker K, Bouhassira D, De Bacquer D, et al. Prevalence and impact on quality of life of peripheral neuropathy with or without neuropathic pain in type 1 and type 2 diabetic patients attending hospital outpatients clinics. Diabetes Metab. 2009;35: 206-213.

7. Callaghan BC, Reynolds E, Banerjee M, Kerber KA, Skolarus LE, Burke JF. Longitudinal pattern of pain medication utilization in peripheral neuropathy patients. Pain. 2019; 160(3):592-599.

8. Dowell D, Haegerich TM, Chou R. CDC guideline for prescribing opioids for chronic pain: United States, 2016. JAMA. 2016;315(15):1624-1645.
9. Franklin GM. Opioids for chronic noncancer pain: a position paper of the American Academy of Neurology. Neurology. 2014;83(14):1277-1284.

10. Kuehn BM. Accelerated overdose deaths linked with COVID-19. JAMA. 2021;325: 523.

11. Bril V, England J, Franklin GM, et al. Evidence-based guideline: treatment of painful diabetic neuropathy: report of the American Academy of Neurology, the American Association of Neuromuscular and Electrodiagnostic Medicine, and the American Academy of Physical Medicine and Rehabilitation. Neurology. 2011;76(20): 1758-1765.

12. Finnerup NB, Attal N, Haroutounian S, et al. Pharmacotherapy for neuropathic pain in adults: systematic review, meta-analysis and updated NeuPSIG recommendations. Lancet Neurol. 2015;14:162-173.

13. Attal N, Cruccu G, Baron R, et al. EFNS guidelines on the pharmacological treatment of neuropathic pain: 2010 revision. Eur J Neurol. 2010;17(9):1113-e88.

14. Waldfogel JM, Nesbit SA, Dy SM, et al. Pharmacotherapy for diabetic peripheral neuropathy pain and quality of life: a systematic review. Neurology;88:1958-1967.

15. Gronseth GS, Cox J, Gloss D, et al. Clinical Practice Guideline Process Manual. American Academy of Neurology; 2017.

16. Raskin J, Pritchett YL, Wang F, et al. A double-blind, randomized multicenter trial comparing duloxetine with placebo in the management of diabetic peripheral neuropathic pain. Pain Med. 2005;6:346-356.

17. Rowbotham MC, Arslanian A, Nothaft W, et al. Efficacy and safety of the alpha4beta2 neuronal nicotinic receptor agonist ABT-894 in patients with diabetic peripheral neuropathic pain. Pain. 2012;153:862-868.

18. Rowbotham MC, Goli V, Kunz NR, Lei D. Venlafaxine extended release in the treatment of painful diabetic neuropathy: a double-blind, placebo-controlled study. Pain. 2004;110(3):697-706.

19. Boyle J, Eriksson ME, Gribble L, et al. Randomized, placebo-controlled comparison of amitriptyline, duloxetine, and pregabalin in patients with chronic diabetic peripheral neuropathic pain: impact on pain, polysomnographic sleep, daytime functioning, and quality of life. Diabetes Care. 2012;35(12):2451-2458.

20. Gao Y, Guo X, Han P, et al. Treatment of patients with diabetic peripheral neuropathic pain in China: a double-blind randomised trial of duloxetine vs. placebo. Int $J$ Clin Pract. 2015;69(9):957-966.

21. Goldstein DJ, Lu Y, Detke MJ, Lee TC, Iyengar S. Duloxetine vs. placebo in patients with painful diabetic neuropathy. Pain. 2005;116(1-2):109-118.

22. Wernicke JF, Pritchett YL, D'Souza DN, et al. A randomized controlled trial of duloxetine in diabetic peripheral neuropathic pain. Neurology. 2006;67(8):1411-1420.

23. Yasuda H, Hotta N, Nakao K, Kasuga M, Kashiwagi A, Kawamori R. Superiority of duloxetine to placebo in improving diabetic neuropathic pain: results of a randomized controlled trial in Japan. J Diabetes Investig. 2011;2(2):132-139.

24. Allen R, Sharma U, Barlas S. Clinical experience with desvenlafaxine in treatment of pain associated with diabetic peripheral neuropathy. J Pain Res. 2014;7:339-351.

25. Eisenberg E, Lurie Y, Braker C, Daoud D, Ishay A. Lamotrigine reduces painful diabetic neuropathy: a randomized, controlled study. Neurology. 2001;57(3):505-509.

26. Shaibani A, Fares S, Selam JL, et al. Lacosamide in painful diabetic neuropathy: an 18 week double-blind placebo-controlled trial. J Pain. 2009;10(8):818-828.

27. Wymer JP, Simpson J, Sen D, Bongardt S, Lacosamide SPSG. Efficacy and safety of lacosamide in diabetic neuropathic pain: an 18-week double-blind placebo-controlled trial of fixed-dose regimens. Clin J Pain. 2009;25:376-385.

28. Dogra S, Beydoun S, Mazzola J, Hopwood M, Wan Y. Oxcarbazepine in painful diabetic neuropathy: a randomized, placebo-controlled study. Eur J Pain. 2005;9(5): 543-554.

29. Kochar DK, Jain N, Agarwal RP, Srivastava T, Agarwal P, Gupta S. Sodium valproate in the management of painful neuropathy in type 2 diabetes: a randomized placebo controlled study. Acta Neurol Scand. 2002;106(5):248-252.

30. Schwartz S, Etropolski M, Shapiro DY, et al. Safety and efficacy of tapentadol ER in patients with painful diabetic peripheral neuropathy: results of a randomizedwithdrawal, placebo-controlled trial. Curr Med Res Opin. 2011;27(1):151-162.

31. Freeman R, Raskin P, Hewitt DJ, et al. Randomized study of tramadol/ acetaminophen vs placebo in painful diabetic peripheral neuropathy. Curr Med Res Opin. 2007;23:147-161.

32. Harati $Y$, Gooch C, Swenson M, et al. Double-blind randomized trial of tramadol for the treatment of the pain of diabetic neuropathy. Neurology. 1998;50(6):1842-1846.

33. Sindrup SH, Andersen G, Madsen C, Smith T, Brøsen K, Jensen TS. Tramadol relieves pain and allodynia in polyneuropathy: a randomised, double-blind, controlled trial. Pain. 1999;83(1):85-90.

34. Tesfaye S, Stevens LK, Stephenson JM, et al. Prevalence of diabetic peripheral neuropathy and its relation to glycaemic control and potential risk factors: the EURODIAB IDDM complications study. Diabetologia. 1996;39(11):1377-1384.

35. Tesfaye S, Chaturvedi N, Eaton SE, et al. Vascular risk factors and diabetic neuropathy. $N$ Engl J Med. 2005;352(4):341-350.

36. Callaghan BC, Xia R, Banerjee M, et al. Metabolic syndrome components are associated with symptomatic polyneuropathy independent of glycemic status. Diabetes Care. 2016;39(5):801-807.

37. Zelman DC, Gore M, Dukes E, Tai KS, Brandenburg N. Validation of a modified version of the brief pain inventory for painful diabetic peripheral neuropathy. J Pain Symptom Manage. 2005;29(4):401-410.

38. Vinik EJ, Hayes RP, Oglesby A, et al. The development and validation of the Norfolk QOL-DN, a new measure of patients' perception of the effects of diabetes and diabetic neuropathy. Diabetes Technol Ther. 2005;7:497-508.

39. Fosnocht DE, Heaps ND, Swanson ER. Patient expectations for pain relief in the ED Am J Emerg Med. 2004;22(4):286-288. 
40. Resnick HE, Redline S, Shahar E, et al. Diabetes and sleep disturbances: findings from the Sleep Heart Health Study. Diabetes Care. 2003;26(3):702-709.

41. Roy T, Lloyd CE. Epidemiology of depression and diabetes: a systematic review. J Affect Disord. 2012;142(suppl):S8-S21.

42. Tang NKY, Salkovskis PM, Hodges A, Wright KJ, Hanna M, Hester J. Effects of mood on pain responses and pain tolerance: an experimental study in chronic back pain patients. Pain. 2008;138(2):392-401.

43. Rosseland R, Pallesen S, Nordhus IH, Matre D, Blågestad T. Effects of sleep fragmentation and induced mood on pain tolerance and pain sensitivity in young healthy adults. Front Psychol. 2018;9:2089.

44. Davies B, Cramp F, Gauntlett-Gilbert J, Wynick D, McCabe C. The role of physical activity and psychological coping strategies in the management of painful diabetic neuropathy: a systematic review of the literature. Physiotherapy. 2015;101:319-326.

45. Williams AC, Fisher E, Hearn L, Eccleston C. Psychological therapies for the management of chronic pain (excluding headache) in adults. Cochrane Database Syst Rev. 2020;8(8):CD007407.

46. Skelly AC, Chou R, Dettori JR, et al. Noninvasive Nonpharmacological Treatment for Chronic Pain: A Systematic Review Update: Comparative Effectiveness Review No. 227 (Prepared by the Pacific Northwest Evidence-based Practice Center under Contract No. 2902015-00009-I): AHRQ Publication No. 20-EHC009. Agency for Healthcare Research and Quality; 2020. Accessed May 18, 2021. doi.org/10.23970/AHRQEPCCER227

47. Knoerl R, Smith EML, Barton DL, et al. Self-guided online cognitive behavioral strategies for chemotherapy-induced peripheral neuropathy: a multicenter, pilot, randomized, wait-list controlled trial. J Pain. 2018;19(4):382-394.

48. Gromisch ES, Kerns RD, Czlapinski R, et al. Cognitive behavioral therapy for the management of multiple sclerosis-related pain: a randomized clinical trial. Int J MS Care. 2020;22:8-14.

49. Gerstner T, Bell N, König S. Oral valproic acid for epilepsy: long-term experience in therapy and side effects. Expert Opin Pharmacother. 2008;9:285-292.

50. Chou R, Turner JA, Devine EB, et al. The effectiveness and risks of long-term opioid therapy for chronic pain: a systematic review for a National Institutes of Health Pathways to Prevention workshop. Ann Intern Med. 2015;162(4):276-286.
51. Krebs EE, Gravely A, Nugent S, et al. Effect of opioid vs nonopioid medications on pain-related function in patients with chronic back pain or hip or knee osteoarthritis pain: the SPACE randomized clinical trial. JAMA. 2018;319(9):872-882.

52. Centers for Disease Control and Prevention. Annual Surveillance Report of DrugRelated Risks and Outcomes: United States: Surveillance Special Report. Centers for Disease Control and Prevention, US Department of Health and Human Services; Published August 31, 2018. Accessed September 11, 2020. cdc.gov/drugoverdose/ pdf/pubs/2018-cdc-drug-surveillance-report.pdf?s_cid=cs_828.

53. Shah A, Hayes CJ, Martin BC. Characteristics of initial prescription episodes and likelihood of long-term opioid use: United States, 2006-2015. MMWR. 2017;66: 265-269.

54. Fulton-Kehoe D, Sullivan M, Turner JA, et al. Opioid poisonings in Washington State Medicaid: trends, dosing, and guidelines. Med Care. 2015;53:679-685.

55. Ultram [package insert]. Janssen Pharmaceuticals Inc; 2019. Accessed August 24, 2020. Available at: accessdata.fda.gov/drugsatfda docs/label/2019/020281s045lbl.pdf.

56. Zeng C, Dubreuil M, LaRochelle MR, et al. Association of tramadol with all-cause mortality among patients with osteoarthritis. JAMA. 2019;321(10):969-982.

57. Abadie D, Rousseau V, Logerot S, Cottin J, Montastruc JL, Montastruc F. Serotonin syndrome: analysis of cases registered in the French pharmacovigilance database. J Clin Psychopharmacol. 2015;35(4):382-388.

58. Vosburg SK, Severtson SG, Dart RC, et al. Assessment of tapentadol API abuse liability with the researched abuse, diversion and addiction-related surveillance System. J Pain. 2018;19:439-453.

59. Nucynta Tablets [package insert]. Collegium Pharmaceutical Inc; 2019. Accessed August 24, 2020. Available at: accessdata.fda.gov/drugsatfda_docs/label/2019/ 022304s022lbl.pdf.

60. Duehmke RM, Derry S, Wiffen PJ, Bell RF, Aldington D, Moore RA. Tramadol for neuropathic pain in adults. Cochrane Database Syst Rev. 2017;6:CD003726.

61. Barohn RJ, Gajewski B, Pasnoor M, et al. Patient-Assisted Intervention for Neuropathy: Comparison of Treatment in Real Life Situations (PAIN-CONTRoLS) Bayesian adaptive comparative effectiveness randomized trial. JAMA Neurol. 2021; 78(1):68-76.

\section{Neurology ${ }^{\circledR}$ Online CME Program}

Earn CME while reading Neurology. This program is available only to online Neurology subscribers. Read the articles marked CME, go to Neurology.org, and click on CME. This will provide all of the information necessary to get started. The American Academy of Neurology (AAN) is accredited by the Accreditation Council for Continuing Medical Education (ACCME) to sponsor continuing medical education for physicians. Neurology is planned and produced in accordance with the ACCME Essentials. For more information, contact AAN Member Services at 800-879-1960.

\section{Share Your Artistic Expressions in Neurology 'Visions'}

AAN members are urged to submit medically or scientifically related artistic images, such as photographs, photomicrographs, and paintings, to the "Visions" section of Neurology ${ }^{\text {. }}$. These images are creative in nature, rather than the medically instructive images published in the NeuroImages section. The image or series of up to six images may be black and white or color and must fit into one published journal page. Accompanying description should be 100 words or less; the title should be a maximum of 140 characters including spaces and punctuation.

Please access the Author Center at NPub.org/authors for full submission information. 


\section{Neurology}

\section{Oral and Topical Treatment of Painful Diabetic Polyneuropathy: Practice Guideline Update Summary: Report of the AAN Guideline Subcommittee \\ Raymond Price, Don Smith, Gary Franklin, et al. \\ Neurology 2022;98;31-43 \\ DOI 10.1212/WNL.0000000000013038}

This information is current as of December 27, 2021

$\begin{array}{ll}\begin{array}{l}\text { Updated Information \& } \\ \text { Services }\end{array} & \begin{array}{l}\text { including high resolution figures, can be found at: } \\ \text { http://n.neurology.org/content/98/1/31.full }\end{array} \\ \text { References } & \text { This article cites } 55 \text { articles, } 9 \text { of which you can access for free at: } \\ & \text { http://n.neurology.org/content/98/1/31.full\#ref-list-1 } \\ & \text { This article has been cited by } 4 \text { HighWire-hosted articles: } \\ & \text { http://n.neurology.org/content/98/1/31.full\#\#otherarticles } \\ \text { Citations } & \text { This article, along with others on similar topics, appears in the } \\ & \text { following collection(s): } \\ \text { Cubspecialty Collections } & \text { http://n.neurology.org/cgi/collection/class_1 } \\ & \text { Class II } \\ & \text { http://n.neurology.org/cgi/collection/class_ii } \\ & \text { Neuropathic pain } \\ & \text { http://n.neurology.org/cgi/collection/neuropathic_pain } \\ & \text { Peripheral neuropathy } \\ & \text { http://n.neurology.org/cgi/collection/peripheral_neuropathy } \\ & \text { Information about reproducing this article in parts (figures,tables) or in } \\ & \text { its entirety can be found online at: } \\ & \text { http://www.neurology.org/about/about_the_journal\#permissions } \\ & \text { Information about ordering reprints can be found online: } \\ \text { Pttp://n.neurology.org/subscribers/advertise }\end{array}$

Updated Information \&

References

Citations

Subspecialty Collections

Neurology ${ }^{\circledR}$ is the official journal of the American Academy of Neurology. Published continuously since 1951, it is now a weekly with 48 issues per year. Copyright @ 2021 American Academy of Neurology. All rights reserved. Print ISSN: 0028-3878. Online ISSN: 1526-632X.

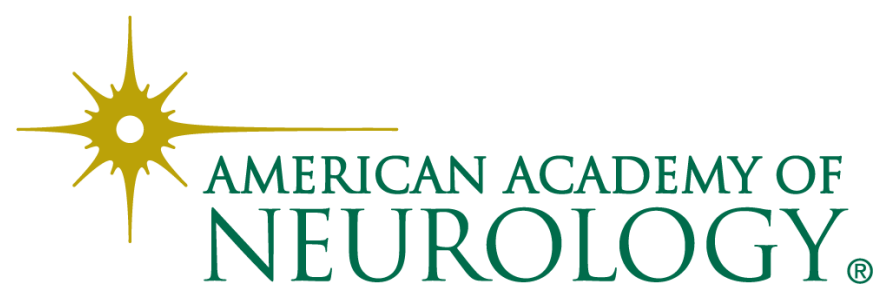

